\title{
A violência contra a mulher idosa no Brasil e os fatores relacionados ao tema: uma revisão integrativa
}

\author{
Jéssica Leitão Morilla ${ }^{\mathrm{a}, *}$, Maria Elisa Gonzalez Manso ${ }^{\mathrm{b}}$ \\ ${ }^{a}$ Universidade Santo Amaro - Unisa, São Paulo - SP, Brazil \\ ${ }^{b}$ Centro Universitário São Camilo - CUSC, São Paulo, SP, Brazil
}

\section{Histórico do Artigo: \\ Recebido em: \\ $16 / 11 / 2020$ \\ Aceito em: \\ $19 / 03 / 2021$}

Palavras-chave:

Violência; idoso; mulher; violência doméstica.

Keywords:

Violence; eldery; woman; domesctic violence.

\begin{abstract}
RESUMO
As vítimas idosas de violência intrafamiliar são predominantemente mulheres. Este fato está relacionando a duas crenças socioculturais da sociedade patriarcal: a mulher deve ser submissa ao homem e a velhice torna o indivíduo sem função social. Objetiva-se analisar as dimensões biopsicossociais da violência contra idosas brasileiras, definir o perfil das vítimas e dos agressores, entender a dinâmica no ambiente de violência, descobrir qual a função das idosas nessas estruturas familiares e a atuação dos mecanismos socais de proteção à pessoa idosa. Tratase de uma revisão integrativa da literatura nas bases SciELO, BVS, CAPES, LILACS e MEDLINE no período entre 2010 a 2020 utilizando os descritores: idosos, mulheres, violência e violência doméstica. Analisando os estudos, as vítimas são mulheres, de 70 anos ou mais, viúvas/divorciadas, aposentadas, com baixa renda e escolaridade. O perfil mais comum de agressor é: filho, de 40 a 49 anos e que faz uso de álcool e/ou drogas e que moram com a vítima. Negligência e violência psicológica são os tipos mais frequentes de violência, entretanto é comum ocorrer mais de um tipo de violência ao mesmo tempo. A família é prioridade para as idosas e para preservá-la, elas escondem as agressões sofridas. Apesar da grande diversidade cultural no Brasil, os trabalhos analisados trouxeram padrões quanto a este tema. Isso mostrou que a violência contra a mulher idosa se encontra pautada em aspectos patriarcais e machistas, sendo importante a criação de políticas públicas que as protejam, uma vez que essas mulheres estão em dois grupos de vulnerabilidade social: mulher e idoso.
\end{abstract}

Violence against elderly women in Brazil and factors related to the theme: an integrative review

\begin{abstract}
Elderly victims of domestic violence are predominantly women. This fact is related to two sociocultural beliefs of patriarchal society: the woman must be submissive to the man and old age renders the individual without a social function. The objective is to analyze the biopsychosocial dimensions of violence against Brazilian elderly women, to define the profile of victims and aggressors, to understand the dynamics in the violence environment, to find out what is the role of elderly women in these family structures and how the social protection mechanisms elderly people works. This is an integrative literature review of SciELO, BVS, CAPES, LILACS e MEDLINE databases from 2010 to 2020 using the descriptors: elderly, women, violence and domestic violence. Analyzing the studies, the victims are women, 70 years old or more, widows/divorced, retired, with low income and education. The most common profile of the aggressor is: son; 40 to 49 years old, uses alcohol and/or drugs and lives with the victim. Negligence and psychological violence are the most frequent types of violence, however it is very common to experience more than one type of violence at the same time. The family is a priority for the elderly women and to preserve it, they hide the aggressions suffered. Despite the great cultural diversity in Brazil, the analyzed works brought standards on this theme. This showed that violence against elderly women is based on patriarchal and sexist aspects, and it is important to create public policies that protect them, since these women are in two groups of social vulnerability: woman and aged.
\end{abstract}

\section{Introdução}

A violência contra a mulher no Brasil pode ser: física, psicológica, sexual, moral e até patrimonial. Na maioria das vezes, esses episódios ocorrem no âmbito privado, o que

\footnotetext{
*Autor correspondente: jessicalmorilla@gmail.com (Morilla J.L.)
} 
dificulta as denúncias (1). Há uma discussão em torno da sociedade patriarcal e conservadora, a qual ainda trata a mulher como subjugada pelo homem. E isso ocorre independentemente da classe social, etnia e cultura, mas há um destaque para a desestrutura familiar. A desigualdade entre os gêneros na sociedade é um problema histórico, que está intimamente ligado aos casos de violência contra a mulher, uma vez que, o companheiro desta é o seu (principal) agressor (2).

A Lei Maria da Penha (3) surge para que a mulher tenha uma proteção em relação ao outro gênero, conseguindo assim atingir o patamar de igualdade com o homem. Essa lei tem como princípio a equidade, oferecendo mais a quem tem mais necessidades e menos a quem requer menos cuidados. Enquanto os homens sofrem violência no espaço público, praticada por outro homem, as mulheres sofrem violência no espaço privado e os agressores são ou foram seus companheiros (4).

Santiago e Coelho (5) em sua análise sobre os antecedentes históricos da violência contra a mulher destacam que muitas esposas se submetem a uma relação do tipo "senhor e escravo" por questões socioculturais. A mulher ainda é vista como objeto de desejo do homem, como seu precioso "bem", mesmo com os movimentos feministas e as mudanças políticas criadas para amenizar um pouco a desigualdade de gênero e suas consequências. Ademais, destaca também que, as políticas públicas ainda não alcançaram resultados favoráveis, por conta da continuidade, aumento e reincidência dos casos de violência.

Outro grupo vulnerável, que acaba por sofrer violência doméstica são as pessoas idosas, sendo este também um problema de saúde pública (6). Com a transição demográfica pela qual o Brasil vem passando, o número de idosos está aumentando em proporção populacional (7) e consequentemente os recursos para manter seus direitos foram surgindo, como o Estatuto do Idoso (8). A violência contra pessoas idosas é uma violação aos direitos humanos e é uma das causas mais importantes de lesões, doenças, perda de produtividade, isolamento e desesperança (9).

O perfil da pessoa idosa vítima de violência intrafamiliar é caracterizado predominantemente por mulher, com no mínimo 75 anos, a qual, muitas vezes, vive com sua família, com uma renda de até dois salários mínimos, sendo viúva, em situação de fragilidade, dependente de um cuidador para suas atividades de vida diária e com vulnerabilidade emocional e psicológica (10).

Segundo a Organização Mundial da Saúde (OMS) (11), violência é "o uso intencional da força física ou do poder real ou em ameaça, contra si próprio, contra outras pessoas, ou contra um grupo ou uma comunidade, que resulte ou tenha qualquer possibilidade de resultar em lesão, morte, dano psicológico, deficiência de desenvolvimento ou privação." Dessa forma, existem inúmeros tipos de violência, entretanto os mais comuns contra as idosas, são: violência física; psicológica; sexual; abandono; negligência; violência financeira ou econômica; autonegligência; violência medicamentosa; emocional e social.

Dados do Disque Direitos Humanos de 2018 (12) mostraram que em relação aos casos de violência contra pessoas idosas denunciados no Brasil, 63\% são mulheres, na faixa etária de 71 a 80 anos, sendo que a maioria se declarou como branca. O local de maior ocorrência dos casos é a própria casa da vítima $(85,5 \%)$. Quanto ao autor da violência, em $53 \%$ dos casos foi o filho da vítima. Na maioria das denúncias, há mais de um tipo de violação apresentada. Dentre os tipos mais comum, estão: negligência (38\%); violência psicológica (26,5\%); abuso financeiro (19,9\%) e violência física (12,5\%).

Para a abordagem e redução dos abusos e violências contra as pessoas idosas, é necessária uma atuação multisetorial e interdisciplinar e que participe os profissionais da justiça e dos direitos humanos, segurança pública, profissionais da saúde, da assistência, instituições religiosas, organizações e associações de idosos, poder legislativos e tantos outros atores e protagonistas sociais (10). 
Observa-se que apesar de já existirem recursos em defesa da mulher e da pessoa idosa, sabe-se que esses dois grupos ainda são vulneráveis. Quando se trata de um indivíduo que se enquadra nos dois grupos mutuamente, essa vulnerabilidade é ainda mais delicada, sendo a mulher idosa uma importante vítima da violência intrafamiliar.

Diante dessas informações, esse estudo tem como objetivo apresentar o estado da arte das pesquisas sobre o tema violência contra mulheres idosas no Brasil, por meio da análise das dimensões da violência contra a idosa em seu aspecto biopsicossocial, assim como os principais tipos de violência sofridos por elas; definir o perfil das vítimas; evidenciar quem são os principais agressores; entender a dinâmica no ambiente de violência; qual a função das idosas nessas estruturas familiares de violência; como é a atuação dos mecanismos sociais de proteção à pessoa idosa e comparar os dados encontrados em cada parte do Brasil.

\section{Materiais e métodos}

Trata-se de uma revisão integrativa da literatura. Utilizou-se de 6 etapas para a construção deste estudo: 1. definição da questão norteadora: Quais são as características da violência contra as mulheres idosas no Brasil em seu aspecto biopsicossocial?; 2. estabelecer os critérios de inclusão e exclusão dos estudos e as bases de dados a serem utilizadas; 3. Categorização dos estudos; 4. avaliação dos artigos; 5. interpretação dos resultados; 6. apresentação da revisão.

Realizou-se, no período de abril a outubro de 2020, uma busca bibliográfica nas bases de dados: Scientific Electronic Library Online (SciELO), Catálogo de Teses e Dissertações do Portal de periódicos da Coordenação de Aperfeiçoamento de pessoal de Nível Superior Brasil (CAPES) e Biblioteca Virtual em Saúde (BVS), incluindo as bases de dados Literatura Latino-americana e do Caribe em Ciências da Saúde (LILACS) e Medical Literature Analysis and Retrieval System Online (MEDLINE). Estas foram selecionadas pois acredita-se serem as principais para o contexto pretendido pelo estudo. Além disso, acrescentou-se teses, dissertações e artigos científicos publicados em revistas não indexadas constantes da base de dados CAPES. Os Descritores em Ciência e Saúde (DeCS) utilizados foram: idosos, mulheres, violência e violência doméstica; e os Medical Subject Headings (MeSH): elder abuse, battered women e domestic violence. A combinação de descritores foi efetuada por meio dos operadores booleanos AND e $O R$.

Foram incluídos os estudos que possuiam as características: estudos com mulheres idosas brasileiras, que tivessem como tema central a violência contra essa parcela da população em especial, produções científicas com texto completo disponível, dissertações e teses em português, inglês e/ou espanhol. O período considerado foi de 2010 a 2020. Optou-se por este intervalo de tempo devido ao pequeno número de artigos, teses e dissertações publicados sobre o tema nos últimos 5 anos, decidindo-se por estender o período considerado.

Como critérios de exclusão foram considerados: os artigos, teses e dissertações que não atendiam os critérios de inclusão; resumos, editoriais, publicações duplicadas e artigos que não abordassem como tema central a violência contra mulheres idosas no Brasil.

Somando-se todas as bases de dados foram encontrados inicialmente quatrocentos e dez (410) artigos que tinham como base de estudo a população brasileira. Por meio da avaliação da relevância para com o tema proposto, foram excluídos artigos que não tinham como tema central violência (de qualquer tipo) contra mulheres brasileiras acima dos 60 anos e os duplicados, conforme apresentado na forma gráfica Figura 1. Resultando em uma amostra de vinte e nove (29) artigos. Estes foram analisados comparativamente e as informações obtidas apresentadas e comentadas durante a discussão. 
J. L. Morilla e M. E. G. Manso / Vittalle v. 33 n. 2 (2021) 66-82

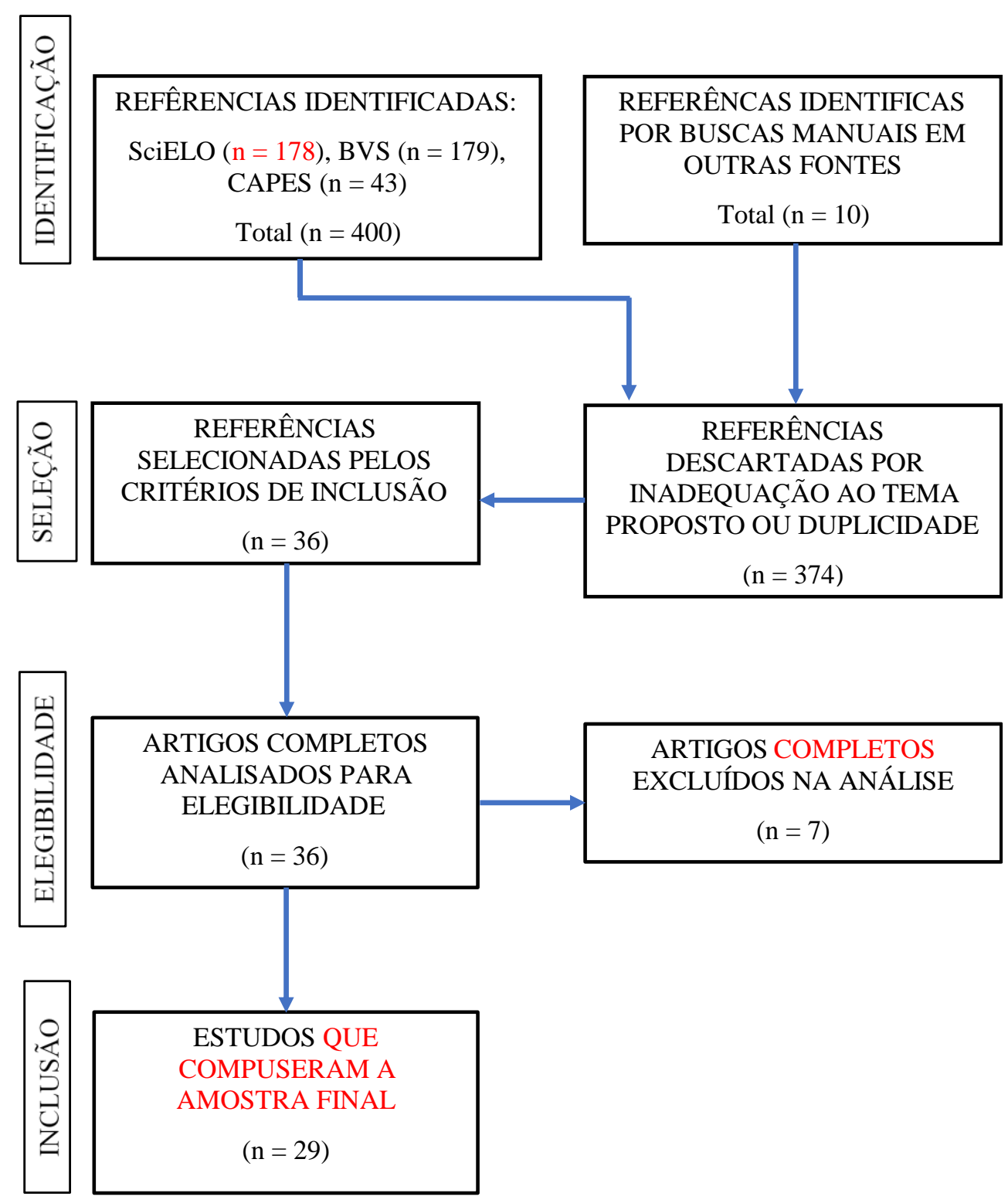

Figura 1 - Fluxograma da seleção de artigos nas bases de dados SciELO, BVS, LILACS, MEDLINE e CAPES no período de 2010 a 2020, com a temática dos descritores: Idosos; Mulheres; Violência; Violência Doméstica.

\section{Resultados}

Após a aplicação dos critérios de elegibilidade, foram incluídos 29 artigos para a amostra final, os quais apresentavam informações relevantes para a construção deste estudo. Esses artigos foram separados em quadros, de acordo com o tema tratado por eles, expondo o título, autor(es), ano publicação e dados de relevância, algum artigos compuseram mais de um quadro. Em seguida, foi feita a análise entre as informações obtidas, construindo-se assim a discussão acerca do tema.

Em relação ao perfil da vítima, 12 artigos trataram desse item, conforme apresentado no Tabela 1. De uma forma geral, o perfil da vítima é: mulher, com 70 anos ou mais, viúvas/divorciadas, aposentadas, com baixa renda e escolaridade. 
Tabela 1 - Descrição dos artigos selecionados para compor a amostra final quanto ao título, autores e ano, segundo o perfil das vítimas de violência contra as mulheres idosas no Brasil.

$\begin{array}{ccc}\text { Título } & \begin{array}{c}\text { Autor(es) / } \\ \text { Ano }\end{array} & \text { Perfil da Vítima }\end{array}$

\begin{tabular}{|c|c|c|}
\hline $\begin{array}{l}\text { "Em que espelho ficou perdida } \\
\text { a minha face?" Um estudo sobre } \\
\text { velhice e violência doméstica } \\
\text { em Fortaleza }\end{array}$ & $\begin{array}{l}\text { De Almeida CO. } \\
2013\end{array}$ & $\begin{array}{l}\text { Mulheres idosas, idade entre } 71 \text { e } 80 \\
\text { anos, viúvas, aposentadas, com baixa } \\
\text { renda e escolaridade, residência própria }\end{array}$ \\
\hline $\begin{array}{l}\text { Prevalence of violence against } \\
\text { the elderly and associated } \\
\text { factors - a population based } \\
\text { study in Florianópolis, Santa } \\
\text { Catarina }\end{array}$ & $\begin{array}{l}\text { Bolsoni CC, } \\
\text { Coelho EBS, } \\
\text { Giehl MWS, } \\
\text { d'Orsi E. } \\
2016\end{array}$ & $\begin{array}{l}\text { Mulheres idosas, solteiras ou } \\
\text { divorciadas, com baixa escolaridade, } \\
\text { dependência moderada à grave, que } \\
\text { coabitam com filhos e netos }\end{array}$ \\
\hline $\begin{array}{l}\text { Profile of aggressors of older } \\
\text { adults receiving care at a } \\
\text { geriatrics and gerontology } \\
\text { reference center in the Distrito } \\
\text { Federal (Federal District), } \\
\text { Brazil }\end{array}$ & $\begin{array}{l}\text { Matos NM, } \\
\text { Albernaz EO, } \\
\text { Sousa BB, Braz } \\
\text { MC, Vale MS, } \\
\text { Pinheiro HA. } \\
2019\end{array}$ & $\begin{array}{l}\text { Mulheres idosas, entre } 71 \text { a } 90 \text { anos, } \\
\text { com baixa renda e com algum grau de } \\
\text { comprometimento cognitivo }\end{array}$ \\
\hline 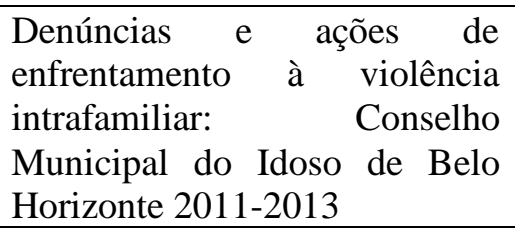 & $\begin{array}{l}\text { Mallet SM. } \\
2015\end{array}$ & $\begin{array}{l}\text { Mulheres idosas, com } 80 \text { anos ou mais, } \\
\text { independentes para as atividades de vida } \\
\text { diária }\end{array}$ \\
\hline $\begin{array}{l}\text { Perfil sociodemográfico y } \\
\text { situaciones de violencia contra } \\
\text { ancianos: estudio descriptivo }\end{array}$ & $\begin{array}{c}\text { Faustino AM, } \\
\text { Moura LBA, } \\
\text { Gandolfi L. } \\
2014 \\
\end{array}$ & $\begin{array}{l}\text { Mulheres idosas dependentes em } \\
\text { atividades básicas de autocuidado, com } \\
\text { menor escolaridade e pior desempenho } \\
\text { no testes mentais }\end{array}$ \\
\hline 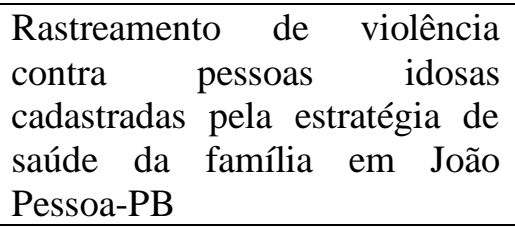 & $\begin{array}{l}\text { Florêncio MVL. } \\
2014\end{array}$ & $\begin{array}{l}\text { Mulheres idosas com déficit cognitivo e } \\
\text { que apresentam sintomas depressivos }\end{array}$ \\
\hline $\begin{array}{l}\text { Análise da violência contra } \\
\text { idosos no município de Pelotas } \\
\text { - RS no ano de } 2012\end{array}$ & $\begin{array}{l}\text { Laroque MF. } \\
2014\end{array}$ & $\begin{array}{l}\text { sexo feminino, com idade variando de } \\
70 \text { a } 89 \text { anos, viúvo (a), alfabetizados, de } \\
\text { cor branca, sem dificuldades para } \\
\text { deambular. recebem menos que um } \\
\text { salário mínimo são mais vitimados }\end{array}$ \\
\hline ontra a pessoa idosa & $\begin{array}{l}\text { Lopes LGF. Leal } \\
\text { MCC, de Souza } \\
\text { EF, da Silva } \\
\text { SZR, Guimarães } \\
\text { NNA, da Silva } \\
\text { LSR. } \\
2018 \\
\end{array}$ & $\begin{array}{l}\text { Homens idosos na faixa etária de } 60-69 \\
\text { anos, de etnia branca, seguida da parda } \\
\text { e casados }\end{array}$ \\
\hline $\begin{array}{l}\text { Violência contra idosos e } \\
\text { qualidade de vida relacionada à } \\
\text { saúde: Estudo populacional no } \\
\text { município de São Paulo, Brasil }\end{array}$ & $\begin{array}{l}\text { Machado DR, } \\
\text { Kimura M, } \\
\text { Duarte YAO, } \\
\text { Lebrão ML. } \\
2020\end{array}$ & $\begin{array}{l}\text { Associado à redução do escore de } \\
\text { componente físico e mental e da } \\
\text { Qualidade de Vida Relacionada à } \\
\text { Saúde, assim como, associações com } \\
\text { incapacidade funcional para atividades } \\
\text { da vida diária, multimorbidade, dor e } \\
\text { sintomas depressivos }\end{array}$ \\
\hline
\end{tabular}


continuação

Maus-tratos contra idosos em Porto Alegre, Rio Grande do Sul: um estudo documental
Irigaray TQ,

Esteves CS, Pacheco JTB, Grassi-Oliveira

R, Argimon IIL. 2016
Mulheres idosas, de baixa escolaridade, em torno de 70 anos, viúvas, solteiras ou separadas, vulneráveis física e mentalmente

$\begin{array}{lcll}\begin{array}{l}\text { Physical and psychological } \\ \text { violence against the elderly: }\end{array} & \text { De Paiva MM, } & \text { Mulheres idosas com idade entre } 60 \text { e } 80 \\ \text { Tavares DMS. } & \text { anos, sem escolaridade, com renda fixa }\end{array}$ prevalence and associated $2014 \quad$ e presença de multimorbidades factors

Violência contra a pessoa idosa: Rodrigues IS. realidades e desafios
Mulheres idosas com a média de idade de 76,3 anos, analfabetas, viúvas, aposentadas, ganhando até um salário mínimo e com doenças crônicas

Oito artigos apresentaram dados sobre o perfil do agressor, disponibilizados no Tabela 2. Sendo predominantemente composto por filhos, do gênero masculino, que se tornam o cuidador da idosa.

Tabela 2 - Descrição dos artigos selecionados para compor a amostra final quanto ao título, autores e ano, segundo o perfil dos agressores das mulheres idosas no Brasil.

\begin{tabular}{|c|c|c|}
\hline Título & Autor(es) / Ano & Perfil do Agressor \\
\hline $\begin{array}{l}\text { "Em que espelho ficou } \\
\text { perdida a minha face?" Um } \\
\text { estudo sobre velhice e violência } \\
\text { doméstica em Fortaleza }\end{array}$ & $\begin{array}{l}\text { De Almeida CO. } \\
2013\end{array}$ & $\begin{array}{l}\text { Filhos ou filhas, com idade entre } 40 \\
\text { e } 49 \text { anos e que fazem uso contínuo } \\
\text { de álcool e/ou drogas }\end{array}$ \\
\hline $\begin{array}{l}\text { Profile of aggressors of older } \\
\text { adults receiving care at a } \\
\text { geriatrics and gerontology } \\
\text { reference center in the Distrito } \\
\text { Federal (Federal District), } \\
\text { Brazil }\end{array}$ & $\begin{array}{c}\text { Matos NM, } \\
\text { Albernaz EO, Sousa } \\
\text { BB, Braz MC, Vale } \\
\text { MS, Pinheiro HA. } \\
2019\end{array}$ & $\begin{array}{l}\text { Filhos, com prevalência do sexo } \\
\text { masculino e faixa etária de } 51 \text { a } 60 \\
\text { anos, cuidador da pessoa idosa }\end{array}$ \\
\hline $\begin{array}{l}\text { Violência } \\
\text { registrada entra pessoa idosa } \\
\text { em delegacia } \\
\text { especializada de Teresina Piauí }\end{array}$ & $\begin{array}{c}\text { Damasceno CKCS, } \\
\text { de Sousa CMM, } \\
\text { Moura MEB. } \\
2016 \\
\end{array}$ & $\begin{array}{l}\text { Familiar, na maioria filho, do sexo } \\
\text { masculino, que depende } \\
\text { financeiramente da vítima e que faz } \\
\text { uso frequente de álcool e drogas }\end{array}$ \\
\hline $\begin{array}{l}\text { Maus-tratos contra idosos em } \\
\text { Porto Alegre, Rio Grande do } \\
\text { Sul: um estudo documental }\end{array}$ & $\begin{array}{c}\text { Irigaray TQ, } \\
\text { Esteves CS, } \\
\text { Pacheco JTB, } \\
\text { Grassi-Oliveira R, } \\
\text { Argimon IIL. } \\
2016 \\
\end{array}$ & $\begin{array}{l}\text { Filhos do sexo masculino, usuários } \\
\text { de drogas ou álcool }\end{array}$ \\
\hline $\begin{array}{l}\text { Violência contra a pessoa idosa: } \\
\text { realidades e desafios }\end{array}$ & $\begin{array}{l}\text { Rodrigues IS. } \\
2015\end{array}$ & $\begin{array}{l}\text { Familiares, na maioria das vezes, } \\
\text { filhos, com média da idade de } 43,2 \\
\text { anos, do sexo masculino e que fazem } \\
\text { uso de bebidas alcoólicas ou outras } \\
\text { drogas }\end{array}$ \\
\hline
\end{tabular}


continuação

\begin{tabular}{|c|c|c|}
\hline $\begin{array}{l}\text { Mapeando expressões de } \\
\text { violência de gênero praticadas } \\
\text { contra idosos/as em Aracaju }\end{array}$ & $\begin{array}{c}\text { De Santana RG, } \\
\text { Oliveira LES, } \\
\text { Cruz MHS, } \\
\text { Silva NL, } \\
\text { Rabelo SF, } \\
\text { Santos VN. } \\
2019\end{array}$ & $\begin{array}{l}\text { Filhos, com mais de } 30 \text { anos, que } \\
\text { dependem financeiramente da idosa }\end{array}$ \\
\hline $\begin{array}{lcc}\text { Mulheres } & \text { idosas vítimas de } \\
\text { violência: estudo de casos } \\
\text { múltiplos }\end{array}$ & $\begin{array}{c}\text { Damaceno DG, } \\
\text { Alarcon MFS, } \\
\text { Sponchiado VBY, } \\
\text { Marin MJS. } \\
2018\end{array}$ & $\begin{array}{l}\text { Filhos, de sexo masculino, com } \\
\text { algum transtorno mental e com } \\
\text { abuso de drogas lícitas e ilícitas, } \\
\text { independente do grau de instrução e } \\
\text { da condição socioeconômica }\end{array}$ \\
\hline $\begin{array}{l}\text { Notification of intrafamily } \\
\text { violence against elderly women } \\
\text { in the city of São Paulo }\end{array}$ & $\begin{array}{l}\text { Guimarães APS, } \\
\text { Górios C, } \\
\text { Rodrigues CL, } \\
\text { Armond JE. } \\
2018\end{array}$ & $\begin{array}{l}\text { Familiares de sexo masculino que } \\
\text { moram com as idosas }\end{array}$ \\
\hline
\end{tabular}

Quanto à dinâmica no ambiente da violência, como mostra a Tabela 3, houve destaque para a coabitação da mesma residência entre vítima e agressor, isolamento o social da vítima, desestrutura familiar, vítima com algum tipo de dependência física ou mental e o motivo da idosa não denunciar é por medo da retaliação e de ser colocada em uma instituição de longa permanência.

Tabela 3 - Descrição dos artigos selecionados para compor a amostra final quanto ao título, autores e ano, segundo a dinâmica no ambiente da violência.

\begin{tabular}{|c|c|c|}
\hline Título & utor(es) / Ano & Dinâmica no ambiente de violência \\
\hline $\begin{array}{l}\text { A Violência Doméstica } \\
\text { Contra a Mulher Idosa: A } \\
\text { busca pelos Aparatos } \\
\text { Sociais de Proteção }\end{array}$ & $\begin{array}{l}\text { Pereira RCBR, de } \\
\text { Loreto MDS. } \\
2019\end{array}$ & $\begin{array}{l}\text { A maioria das idosas não denuncia as } \\
\text { agressões que sofrem ou desistem de dar } \\
\text { continuidade à denúncia. Elas têm } \\
\text { conhecimento sobre a lei Maria da Penha e } \\
\text { o Estatuto do Idoso, mas não sabiam que ao } \\
\text { fazerem uma denúncia, estariam utilizando } \\
\text { esses instrumentos }\end{array}$ \\
\hline $\begin{array}{l}\text { Violência contra pessoas } \\
\text { idosas: narrativas de } \\
\text { agressores }\end{array}$ & 6 & $\begin{array}{l}\text { A violência está relacionada à desestrutura } \\
\text { familiar, ao desemprego e ao consumo } \\
\text { abusivo de álcool e/ou outros drogas } \\
\text { ilícitas. As idosas omitem a denúncia por } \\
\text { medo da retaliação }\end{array}$ \\
\hline $\begin{array}{l}\text { Profile of aggressors of } \\
\text { older adults receiving care } \\
\text { at a geriatrics and } \\
\text { gerontology reference } \\
\text { center in the Distrito } \\
\text { Federal (Federal District), } \\
\text { Brazil }\end{array}$ & $\begin{array}{l}\text { Matos NM, } \\
\text { Albernaz EO, } \\
\text { Sousa BB, Braz } \\
\text { MC, Vale MS, } \\
\text { Pinheiro HA. } \\
2019\end{array}$ & $\begin{array}{l}\text { Agressor é o cuidador da pessoa idosa, mas } \\
\text { desconhece os sintomas das doenças e as } \\
\text { necessidades que ela possui. As idosas não } \\
\text { denunciam por medo de serem colocadas } \\
\text { em instituições de longa permanência, por } \\
\text { acreditarem que a impaciência e as } \\
\text { agressões são justificáveis e por respeito } \\
\text { aos laços familiares entre o agressor e a } \\
\text { vítima }\end{array}$ \\
\hline $\begin{array}{lr}\text { Ecos da } & \text { violência: } \\
\text { significados } & \text { e } \\
\text { repercussões em idosos }\end{array}$ & $\begin{array}{c}\text { De Castro AP. } \\
2013\end{array}$ & $\begin{array}{l}\text { Idosas tentam se adaptar ao ambiente de } \\
\text { violência, tratando a situação com } \\
\text { naturalização. Quando denunciam, se sentem } \\
\text { angustiadas, depressivas e com medo }\end{array}$ \\
\hline
\end{tabular}


continuação

\begin{tabular}{|c|c|c|}
\hline $\begin{array}{l}\text { Violência contra pessoa } \\
\text { idosa registrada em } \\
\text { delegacia especializada de } \\
\text { Teresina Piauí }\end{array}$ & $\begin{array}{l}\text { Damasceno } \\
\text { CKCS, de Sousa } \\
\text { CMM, Moura } \\
\text { MEB. } \\
2016 \\
\end{array}$ & $\begin{array}{l}\text { As vítimas são mantidas em isolamento } \\
\text { social pelo agressor. A deterioração e a } \\
\text { fragilização das relações familiares } \\
\text { caracterizam o ambiente }\end{array}$ \\
\hline $\begin{array}{l}\text { Perfil sociodemográfico y } \\
\text { situaciones de violencia } \\
\text { contra ancianos: estudio } \\
\text { descriptivo }\end{array}$ & $\begin{array}{l}\text { Faustino AM, } \\
\text { Moura LBA, } \\
\text { Gandolfi L. } \\
2014 \\
\end{array}$ & $\begin{array}{l}\text { Agressor mora com a vítima, e muitas vezes } \\
\text { depende dela financeiramente, ou a vítima } \\
\text { que depende do agressor. Ambiente de } \\
\text { pobreza e falta de apoio social }\end{array}$ \\
\hline $\begin{array}{l}\text { Rastreamento de violência } \\
\text { contra pessoas idosas } \\
\text { cadastradas pela estratégia } \\
\text { de saúde da família em } \\
\text { João Pessoa-PB }\end{array}$ & $\begin{array}{c}\text { Florêncio MVL. } \\
2014\end{array}$ & $\begin{array}{l}\text { Desunião familiar e histórico prévio de } \\
\text { violência familiar, além de idosa com } \\
\text { sintomas depressivos }\end{array}$ \\
\hline $\begin{array}{lrrr}\text { Crença } & \text { de } & \text { gestores } & \text { de } \\
\text { Saúde em relação } & \text { à } \\
\text { violência doméstica } & \end{array}$ & $\begin{array}{l}\text { Lourenço LM, de } \\
\text { Paula Junior GV. } \\
\quad 2020\end{array}$ & $\begin{array}{l}\text { Família não tem paciência, informação e } \\
\text { nem perfil adequado para cuidar da idosa. } \\
\text { Interesse de usufruir dos benefícios } \\
\text { financeiros da idosa }\end{array}$ \\
\hline $\begin{array}{l}\text { Violência contra idosos e } \\
\text { qualidade de vida } \\
\text { relacionada à saúde: } \\
\text { Estudo populacional no } \\
\text { município de São Paulo, } \\
\text { Brasil }\end{array}$ & $\begin{array}{l}\text { Machado DR, } \\
\text { Kimura M, } \\
\text { Duarte YAO, } \\
\text { Lebrão ML. } \\
2020\end{array}$ & $\begin{array}{l}\text { Idosas não relatam a violência sofrida por } \\
\text { medo da retaliação, de desestruturar a } \\
\text { família, perder autonomia ou o local de } \\
\text { residência - maioria vive com o agressor }\end{array}$ \\
\hline $\begin{array}{l}\text { Violência silenciada: } \\
\text { violência física e } \\
\text { psicológica contra idosos } \\
\text { no contexto familiar }\end{array}$ & $\begin{array}{l}\text { Martins MB. } \\
2013\end{array}$ & $\begin{array}{l}\text { Foi observado o desconhecimento por parte } \\
\text { das idosas dos vários tipos de violência e a } \\
\text { dificuldade emocional que as idosas têm em } \\
\text { aceitar que seus familiares sejam os } \\
\text { protagonistas de atos violentos contra elas } \\
\text { dentro de seus lares }\end{array}$ \\
\hline $\begin{array}{l}\text { Gênero, Velhice e } \\
\text { Geração: a violência } \\
\text { familiar contra a mulher } \\
\text { idosa em Vitória (ES), } \\
2010-2012\end{array}$ & $\begin{array}{l}\text { Silveira L. } \\
2015\end{array}$ & $\begin{array}{l}\text { Uma relação de poder do filho e do neto em } \\
\text { relação à mãe ou avó. O uso de álcool e } \\
\text { drogas pelo agressor, a dependência } \\
\text { econômica e a pobreza caracterizam o } \\
\text { ambiente }\end{array}$ \\
\hline $\begin{array}{lr}\text { Older Brazilian } & \text { women's } \\
\text { experience r of } & \text { of } \\
\text { psychological domestic } \\
\text { violence: a social } \\
\text { phenomenological study }\end{array}$ & $\begin{array}{c}\text { Souto RQ, } \\
\text { Merighi MAB, } \\
\text { Guruge S, de Jesus } \\
\text { MCP. } \\
2015 \\
\end{array}$ & $\begin{array}{l}\text { Mulheres idosas manifestam compaixão } \\
\text { pelo seu agressor e necessita de apoio para } \\
\text { conviver com a violência ou tentar } \\
\text { enfrentá-la }\end{array}$ \\
\hline $\begin{array}{l}\text { Mapeando expressões de } \\
\text { violência de gênero } \\
\text { praticadas contra idosos/as } \\
\text { em Aracaju }\end{array}$ & $\begin{array}{c}\text { De Santana RG, } \\
\text { Oliveira LES, } \\
\text { Cruz MHS, } \\
\text { Silva NL, } \\
\text { Rabelo SF, } \\
\text { Santos VN. } \\
2019 \\
\end{array}$ & $\begin{array}{l}\text { Maioria das vítimas ficam em isolamento } \\
\text { social, tendo contato apenas com alguns } \\
\text { familiares - vindo a prejudicar o processo } \\
\text { de denúncia. O agressor depende } \\
\text { financeiramente da vítima }\end{array}$ \\
\hline
\end{tabular}


continuação

\begin{tabular}{|c|c|c|}
\hline $\begin{array}{l}\text { Mulheres idosas vítimas } \\
\text { de violência: estudo de } \\
\text { casos múltiplos }\end{array}$ & $\begin{array}{c}\text { Damaceno DG, } \\
\text { Alarcon MFS, } \\
\text { Sponchiado VBY, } \\
\text { Marin MJS. } \\
2018\end{array}$ & $\begin{array}{l}\text { Vítima e agressor têm uma relação de dupla } \\
\text { face de dependência. Vítimas têm } \\
\text { dificuldade no acesso a serviços e } \\
\text { desenvolvem vários sentimentos em } \\
\text { relação aos seus agressores: tristeza, medo, } \\
\text { sofrimento, amor e compaixão tentando } \\
\text { proteger e justificar os atos }\end{array}$ \\
\hline $\begin{array}{l}\text { Maus-tratos a idosos no } \\
\text { Brasil: uma revisão } \\
\text { integrativa }\end{array}$ & $\begin{array}{c}\text { Lopes EDS, } \\
\text { Ferreira AG, Pires } \\
\text { AG, Moraes MCS, } \\
\text { D’Elboux MJ. } \\
2018\end{array}$ & $\begin{array}{l}\text { O principal local de ocorrência de maus- } \\
\text { tratos é a própria residência da vítima. } \\
\text { Contexto familiar estressante e com } \\
\text { cuidadores despreparados } \\
\text { sobrecarregados, familiares, geralmente, } \\
\text { assumem o papel de cuidadores de seus } \\
\text { idosos de forma voluntária e informal, sem } \\
\text { preparo }\end{array}$ \\
\hline
\end{tabular}

De acordo com a Tabela 4, as dimensões da violência mostram que os tipos mais frequentes de violência são: negligência e psicológica, seguidos de financeiro, verbal e física. Na sua grande maioria, geram sequelas nessas idosas, como: depressão e/ou ansiedade, síndrome do pânico, emagrecimento, picos hipertensivos, entre outros.

Tabela 4 - Descrição dos artigos selecionados para compor a amostra final quanto ao título, autores e ano, segundo as dimensões da violência sofrida.

\begin{tabular}{|c|c|c|}
\hline Título & Autor(es) / Ano & Dimensões da violência \\
\hline $\begin{array}{l}\text { Violência contra pessoas idosas: } \\
\text { narrativas de agressores }\end{array}$ & $\begin{array}{l}\text { Bohm V. } \\
2016\end{array}$ & $\begin{array}{l}\text { Tipo de violência negligência, } \\
\text { psicológica e financeira, entretanto } \\
\text { é comum mais de um tipo }\end{array}$ \\
\hline $\begin{array}{l}\text { Prevalence of violence against the } \\
\text { elderly and associated factors - a } \\
\text { population based study in } \\
\text { Florianópolis, Santa Catarina }\end{array}$ & $\begin{array}{l}\text { Bolsoni CC, Coelho } \\
\text { EBS, Giehl MWS, } \\
\text { d’Orsi E. } \\
2016\end{array}$ & $\begin{array}{l}\text { Tipos de violência: verbal, } \\
\text { financeira e psicológica. As } \\
\text { sequelas geradas para as idosas são: } \\
\text { estado geral de saúde ruim, } \\
\text { problemas estomacais, dores de } \\
\text { cabeça, sobrepeso, alergias, } \\
\text { ansiedade, problemas para dormir e } \\
\text { estresse }\end{array}$ \\
\hline
\end{tabular}

\begin{tabular}{lccl}
\hline $\begin{array}{l}\text { Violência contra pessoa idosa } \\
\text { registrada em delegacia } \\
\text { especializada de Teresina Piauí }\end{array}$ & $\begin{array}{c}\text { Damasceno CKCS, } \\
\text { de Sousa CMM, } \\
\text { Moura MEB. } \\
2016\end{array}$ & $\begin{array}{l}\text { Tipos de violência: financeira, } \\
\text { psicológica, verbal e física. Como } \\
\text { sequelas para as idosas, pode-se } \\
\text { citar: depressão, síndrome do } \\
\text { pânico e até a morte }\end{array}$ \\
\hline $\begin{array}{l}\text { Violência contra idosos e } \\
\text { qualidade de vida relacionada à } \\
\text { saúde: Estudo populacional no } \\
\text { município de São Paulo, Brasil }\end{array}$ & $\begin{array}{c}\text { Machado DR, } \\
\text { Kimura M, } \\
\text { Duarte YAO, } \\
\text { Lebrão ML. }\end{array}$ & $\begin{array}{l}\text { Sequelas para as idosas: sentimento } \\
\text { de raiva, desmoralização, } \\
\text { vergonha, humilhação, medo, } \\
\text { isolamento social, insônia, falta de } \\
\text { apetite, indigestão, solidão, tristeza } \\
\text { e infelicidade diante da vida }\end{array}$ \\
\hline
\end{tabular}


continuação

Older Brazilian women's $\quad$ Souto RQ, $\quad$ Tipos de violência: abusos
experience of psychological Merighi MAB, psicológicos e financeiro, e domestic violence: a social Guruge $\mathrm{S}$, de Jesus negligências. Como sequelas: phenomenological study MCP. 2015 sentimento de tristeza, raiva, pesar e medo, que tiveram efeitos negativos em sua saúde. Pelo insucesso das tentativas de mudar sua situação atual, elas se sentiam impotentes

\begin{tabular}{|c|c|c|}
\hline $\begin{array}{lccc}\text { Mulheres } & \text { idosas } & \text { vítimas } & \text { de } \\
\text { violência: } & \text { estudo } & \text { de } & \text { casos } \\
\text { múltiplos } & & & \end{array}$ & $\begin{array}{c}\text { Damaceno DG, } \\
\text { Alarcon MFS, } \\
\text { Sponchiado VBY, } \\
\text { Marin MJS. } \\
2018\end{array}$ & $\begin{array}{l}\text { Como sequelas para as idosas: } \\
\text { sofrimento psicológico } \\
\text { evidenciado por manifestações } \\
\text { físicas, como: emagrecimento } \\
\text { excessivo, a inapetência e os picos } \\
\text { hipertensivos }\end{array}$ \\
\hline $\begin{array}{l}\text { Maus-tratos a idosos no Brasil: } \\
\text { uma revisão integrativa }\end{array}$ & $\begin{array}{c}\text { Lopes EDS, } \\
\text { Ferreira AG, Pires } \\
\text { AG, Moraes MCS, } \\
\text { D’Elboux MJ. } \\
2018 \\
\end{array}$ & $\begin{array}{l}\text { Tipos de violência: psicológica, } \\
\text { física, financeira, autoabandono, } \\
\text { negligência e violência verbal }\end{array}$ \\
\hline $\begin{array}{l}\text { Profile of aggressors of older } \\
\text { adults receiving care at a } \\
\text { geriatrics and gerontology } \\
\text { reference center in the Distrito } \\
\text { Federal (Federal District), Brazil }\end{array}$ & $\begin{array}{l}\text { Matos NM, } \\
\text { Albernaz EO, } \\
\text { Sousa BB, Braz } \\
\text { MC, Vale MS, } \\
\text { Pinheiro HA. } \\
2019\end{array}$ & $\begin{array}{l}\text { Tipos de violência: negligência, } \\
\text { violência psicológica e física }\end{array}$ \\
\hline 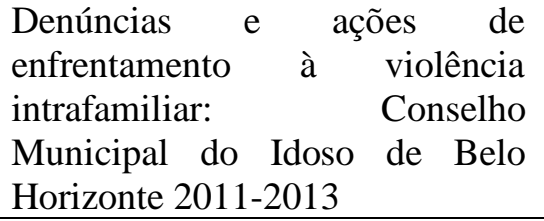 & $\begin{array}{l}\text { Mallet SM. } \\
\quad 2015\end{array}$ & $\begin{array}{l}\text { Tipos de violência: negligência, } \\
\text { psicológica e abandono; as vítimas } \\
\text { sofrem dois ou mais tipos de } \\
\text { violência }\end{array}$ \\
\hline $\begin{array}{l}\text { Perfil sociodemográfico y } \\
\text { situaciones de violencia contra } \\
\text { ancianos: estudio descriptivo }\end{array}$ & $\begin{array}{l}\text { Faustino AM, } \\
\text { Moura LBA, } \\
\text { Gandolfi L. } \\
2014\end{array}$ & $\begin{array}{l}\text { Tipos de violência: violência } \\
\text { psicológica, agressão física, } \\
\text { abandono e abuso financeiro }\end{array}$ \\
\hline $\begin{array}{l}\text { Prevalência, fatores associados e } \\
\text { efeitos da violência doméstica na } \\
\text { mobilidade em idosos: evidências } \\
\text { do estudo imias (international } \\
\text { mobility in aging study) sob a } \\
\text { perspectiva epidemiológica do } \\
\text { curso da vida }\end{array}$ & $\begin{array}{l}\text { Guedes DT. } \\
2015\end{array}$ & $\begin{array}{l}\text { Tipos de violência: violência } \\
\text { psicológica e física, sendo essa } \\
\text { última associada com sequelas de } \\
\text { limitações físicas }\end{array}$ \\
\hline $\begin{array}{l}\text { Maus-tratos contra idosos em } \\
\text { Porto Alegre, Rio Grande do Sul: } \\
\text { um estudo documental }\end{array}$ & $\begin{array}{c}\text { Irigaray TQ, } \\
\text { Esteves CS, } \\
\text { Pacheco JTB, } \\
\text { Grassi-Oliveira R, } \\
\text { Argimon IIL. } \\
2016 \\
\end{array}$ & $\begin{array}{l}\text { Tipos de violência: maus-tratos } \\
\text { psicológicos e abuso financeiro ou } \\
\text { material }\end{array}$ \\
\hline $\begin{array}{l}\text { Physical and psychological } \\
\text { violence against the elderly: } \\
\text { prevalence and associated factors }\end{array}$ & $\begin{array}{l}\text { De Paiva MM, } \\
\text { Tavares DMS. } \\
2014\end{array}$ & $\begin{array}{llll}\text { Tipos de } & \text { violência: física } & \mathrm{e} \\
\text { psicológica }\end{array}$ \\
\hline
\end{tabular}


continuação

\begin{tabular}{lcl}
\hline $\begin{array}{l}\text { Violência contra o idoso no } \\
\text { estado de Minas Gerais: análise } \\
\text { das notificaçoses em 2009 e 2012 }\end{array}$ & $\begin{array}{c}\text { De Rende MM. } \\
\text { Viole }\end{array}$ & Tipo de violência: física \\
\hline $\begin{array}{l}\text { Violência contra a pessoa idosa: } \\
\text { realidades e desafios }\end{array}$ & $\begin{array}{c}\text { Rodrigues IS. } \\
2015\end{array}$ & $\begin{array}{l}\text { Tipo de violência: psicológica, } \\
\text { abuso financeiro/econômico e e } \\
\text { negligência }\end{array}$ \\
\hline $\begin{array}{l}\text { Perfil da violência cometida } \\
\begin{array}{l}\text { contra a pessoa idosa registrada } \\
\text { no disque direitos humanos no } \\
\text { período de 2011-2015 no Brasil }\end{array}\end{array}$ & $\begin{array}{c}\text { Taveira LM, } \\
\text { Oliveira MLC. }\end{array}$ & $\begin{array}{l}\text { Tipo de violência: negligência, } \\
\text { psicológica e abuso financeiro }\end{array}$ \\
\hline
\end{tabular}

A principal função da idosa nessa estrutura familiar de violência, conforme o Tabela 5, é ser a provedora da renda dessa família ou do agressor.

Tabela 5 - Descrição dos artigos selecionados para compor a amostra final quanto ao título, autores e ano, segundo a função da idosa na estrutura familiar.

\begin{tabular}{|c|c|c|}
\hline Título & $\begin{array}{c}\text { Autor(es) / } \\
\text { Ano }\end{array}$ & $\begin{array}{l}\text { Função da idosa na estrutura } \\
\text { familiar de violência }\end{array}$ \\
\hline $\begin{array}{l}\text { Violência contra pessoas idosas: } \\
\text { narrativas de agressores }\end{array}$ & $\begin{array}{l}\text { Bohm V. } \\
2016\end{array}$ & $\begin{array}{l}\text { A renda das pessoas idosas é um } \\
\text { importante recurso para o sustento da } \\
\text { família }\end{array}$ \\
\hline $\begin{array}{l}\text { "Em que espelho ficou perdida a } \\
\text { minha face?" Um estudo sobre } \\
\text { velhice e violência doméstica em } \\
\text { Fortaleza }\end{array}$ & $\begin{array}{l}\text { De Almeida } \\
\text { CO. } \\
2013\end{array}$ & $\begin{array}{l}\text { A aposentadoria da idosa compõe a } \\
\text { renda familiar }\end{array}$ \\
\hline $\begin{array}{l}\text { Profile of aggressors of older adults } \\
\text { receiving care at a geriatrics and } \\
\text { gerontology reference center in the } \\
\text { Distrito Federal (Federal District), } \\
\text { Brazil }\end{array}$ & $\begin{array}{l}\text { Matos NM, } \\
\text { Albernaz EO, } \\
\text { Sousa BB, Braz } \\
\text { MC, Vale MS, } \\
\text { Pinheiro HA. } \\
2019 \\
\end{array}$ & $\begin{array}{l}\text { Idosa depende financeiramente } \\
\text { fisicamente dos seus familiares }\end{array}$ \\
\hline $\begin{array}{lcr}\text { Violência } & \text { contra pessoa idosa } \\
\text { registrada } & \text { em } & \text { delegacia } \\
\text { especializada de Teresina Piauí }\end{array}$ & $\begin{array}{l}\text { Damasceno } \\
\text { CKCS, de } \\
\text { Sousa CMM, } \\
\text { Moura MEB. } \\
2016\end{array}$ & $\begin{array}{l}\text { Finanças da idosa são a renda seu do } \\
\text { agressor }\end{array}$ \\
\hline $\begin{array}{l}\text { Rastreamento de violência contra } \\
\text { pessoas idosas cadastradas pela } \\
\text { estratégia de saúde da família em } \\
\text { João Pessoa-PB }\end{array}$ & $\begin{array}{l}\text { Florêncio } \\
\text { MVL. } \\
2014\end{array}$ & $\begin{array}{l}\text { As idosas são as maiores ou as únicas } \\
\text { responsáveis pela renda familiar }\end{array}$ \\
\hline $\begin{array}{l}\text { Análise da violência contra idosos } \\
\text { no município de Pelotas - RS no } \\
\text { ano de } 2012\end{array}$ & $\begin{array}{l}\text { Laroque MF. } \\
\quad 2014\end{array}$ & $\begin{array}{l}\text { A maioria das idosas é a única fonte } \\
\text { de renda para a família }\end{array}$ \\
\hline
\end{tabular}

Fonte: Resultado da pesquisa (2020)

A Tabela 6 apresenta os artigos que englobaram a atuação dos mecanismos sociais de proteção às pessoas idosas. 
Tabela 6 - Descrição dos artigos selecionados para compor a amostra final quanto ao título, autores e ano, segundo a atuação dos mecanismos sociais de proteção às pessoas idosas.

\begin{tabular}{|c|c|c|}
\hline Título & Autor(es) / Ano & $\begin{array}{c}\text { Atuação dos mecanismos sociais de } \\
\text { proteção às pessoas idosas }\end{array}$ \\
\hline $\begin{array}{l}\text { A Violência Doméstica } \\
\text { Contra a Mulher Idosa: A } \\
\text { busca pelos Aparatos } \\
\text { Sociais de Proteção }\end{array}$ & $\begin{array}{l}\text { Pereira RCBR, de } \\
\text { Loreto MDS. } \\
2019\end{array}$ & $\begin{array}{l}\text { A resolução que ocasionou a separação do } \\
\text { agressor e da vítima, resultou em } \\
\text { melhorias em suas vidas, com o termino da } \\
\text { violência }\end{array}$ \\
\hline 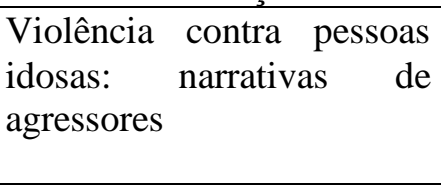 & $\begin{array}{l}\text { Bohm V. } \\
2016\end{array}$ & $\begin{array}{l}\text { Identificou-se uma atuação precária dos } \\
\text { mecanismos sociais de proteção à pessoa } \\
\text { idosa, que não conseguem garantir a sua } \\
\text { segurança }\end{array}$ \\
\hline $\begin{array}{l}\text { Profile of aggressors of } \\
\text { older adults receiving care } \\
\text { at a geriatrics and } \\
\text { gerontology reference } \\
\text { center in the Distrito } \\
\text { Federal (Federal District), } \\
\text { Brazil }\end{array}$ & $\begin{array}{l}\text { Matos NM, } \\
\text { Albernaz EO, } \\
\text { Sousa BB, Braz } \\
\text { MC, Vale MS, } \\
\text { Pinheiro HA. } \\
2019\end{array}$ & $\begin{array}{l}\text { Apesar do desenvolvimento de políticas } \\
\text { públicas para proteção da pessoa idosa, } \\
\text { elas não são efetivas ainda, carecendo de } \\
\text { eficácia e continuidade }\end{array}$ \\
\hline $\begin{array}{l}\text { Rastreamento de violência } \\
\text { contra pessoas idosas } \\
\text { cadastradas pela estratégia } \\
\text { de saúde da família em João } \\
\text { Pessoa-PB }\end{array}$ & $\begin{array}{l}\text { Florêncio MVL. } \\
2014\end{array}$ & $\begin{array}{l}\text { O rastreamento do risco e da violência } \\
\text { contra a pessoa idosa é uma ação possível } \\
\text { de ser realizada no ambiente de prática da } \\
\text { atenção básica e pode oferecer parâmetros } \\
\text { para a identificação precoce da situação de } \\
\text { risco, antecipando intervenções e } \\
\text { prevenindo agravos }\end{array}$ \\
\hline $\begin{array}{l}\text { Percepção de idosos e } \\
\text { profissionais do serviço de } \\
\text { convivência em Sobral } \\
\text { sobre riolência } \\
\text { institucional nos serviços de } \\
\text { saúde }\end{array}$ & $\begin{array}{l}\text { Barros APM. } \\
2016\end{array}$ & $\begin{array}{l}\text { Apontaram dificuldades enfrentadas pelas } \\
\text { pessoas idosas como a peregrinação em } \\
\text { busca de atendimentos, a falta de } \\
\text { medicamentos, o desrespeito dos } \\
\text { profissionais }\end{array}$ \\
\hline $\begin{array}{l}\text { Mapeando expressões de } \\
\text { violência de gênero } \\
\text { praticadas contra idosos/as } \\
\text { em Aracaju }\end{array}$ & $\begin{array}{l}\text { De Santana RG, } \\
\text { Oliveira LES, } \\
\text { Cruz MHS, } \\
\text { Silva NL, } \\
\text { Rabelo SF, } \\
\text { Santos VN. } \\
2019 \\
\end{array}$ & $\begin{array}{l}\text { O combate às várias expressões de } \\
\text { violência contra as pessoas idosas é feita } \\
\text { através das políticas existentes, como o } \\
\text { assistente social que acompanha as } \\
\text { famílias, quando há situações que colocam } \\
\text { em risco a unidade familiar }\end{array}$ \\
\hline $\begin{array}{l}\text { Mulheres idosas vítimas de } \\
\text { violência: estudo de casos } \\
\text { múltiplos }\end{array}$ & $\begin{array}{l}\text { Damaceno DG, } \\
\text { Alarcon MFS, } \\
\text { Sponchiado VBY, } \\
\text { Marin MJS. } \\
2018 \\
\end{array}$ & $\begin{array}{l}\text { Observou-se grande dificuldade dos } \\
\text { serviços responsáveis pelo atendimento às } \\
\text { pessoas idosas }\end{array}$ \\
\hline
\end{tabular}

\section{Discussão}

A construção sociocultural de desvalorização da pessoa idosa está intimamente relacionada com os casos de violência contra ela. Como consequência, é comum na sociedade o medo e a insegurança em relação ao processo de envelhecimento (13).

O estudo realizado por Taveira e de Oliveira (14) com base nos registros do Disque Direitos Humanos constatou que, a incidência da violência por regiões geográficas 
brasileiras foi maior na região Sudeste $(42,2 \%)$, seguida pela Nordeste $(28,4 \%)$, Sul (14\%), Centro-Oeste $(8,4 \%)$ e Norte $(6,6 \%)$ no período de 2011-2015. Além disso, foi observado um crescimento do registro da violência neste período em comparação aos períodos anteriores.

De acordo com estudos feitos em várias regiões do Brasil, as principais vítimas da violência contra a pessoa idosa são: mulheres, com idade a partir dos 70 anos, viúvas/divorciadas, aposentadas, com baixa renda e escolaridade, que muitas vezes apresentam algum comprometimento físico e/ou cognitivo, que têm residência própria, coabitando com seus próprios agressores $(15,16,17,18,19,20,21,22,23,24,25)$, que em geral são filhos (majoritariamente do sexo masculino), com idade entre 40 e 49 anos e que fazem uso contínuo de álcool e/ou drogas $(17,18,19,23,26,27,28,29)$.

Ainda sobre o agressor, o filho se revela o cuidador da pessoa idosa $(6,15,18,20,21,23,24,29,30)$. A adaptação para o cuidar familiar gera algumas dificuldades, como: transformações no estilo de vida, intolerância, incompreensão e indisposição. Isso faz com que a dificuldade de cuidar se aproxime de atos violentos (31). Além disso, muitos cuidadores familiares não sabem reconhecer os sintomas das doenças que a idosa possui e não se atentam as suas necessidades (23), uma vez que, geralmente, eles assumem esse papel sem um preparo prévio (6).

Foi constatado no estudo de Bolsoni et al. (24), que as mulheres idosas sofrem duas vezes mais violência do que os homens, dado confirmado pelas informações apresentadas no Disque Direitos Humanos (12). Isso está relacionado com o fato de as idosas, em geral, possuírem mais doenças crônicas e mais incapacidades funcionais do que os homens idosos (21).

Ainda sobre o tema, a dependência moderada a grave mostrou-se fortemente associada a este desfecho. Uma vez, dependente, a idosa se torna mais susceptível a sofrer violência sem que o agressor seja acusado ou denunciado. Quando apresentam limitações e doenças que demandam maior cuidado, aumenta a probabilidade de sofrer violência $(12,15,24)$. Foi evidenciado nos trabalhos analisados, a relação entre ser dependente em atividades básicas de autocuidado e sofrimento de violência física $(15,26)$.

Quanto à dimensão dessa violência, a negligência, na maioria dos estudos, é o tipo de violência que mais se destaca, junto com a psicológica $(14,15,19,20,21,23,32)$. Entretanto, é muito comum dois ou mais tipos de violência associados $(12,19,20)$. A psicológica aumenta a possibilidade de as demais ocorrerem, pois colocam a pessoa idosa em situação de humilhação e medo, permitindo que o agressor mantenha ou cometa outros tipos de abusos $(15,24,32)$.

A maioria dos casos de violência intrafamiliar contra as idosas se sustenta pelo silêncio da família, que trata a violência como assunto particular, e, às vezes, até naturalizado $(4,11,13)$.

A violência contra a mulher, diferente das que ocorrem com os homens, se caracteriza por ser dentro do seu próprio lar $(6,12,27,33)$. Martins (4) ainda destaca que a violência contra mulheres idosas, tem que ser entendida em suas determinações históricas de uma sociedade patriarcal, na qual a vontade do homem ainda se sobrepõe à da mulher e a vontade dos mais jovens se sobrepõe a dos mais idosos $(4,26)$, estabelecendo-se uma relação de poder entre o agressor e a vítima.

Dentre as sequelas que essas situações de violência podem gerar para a idosa, pode-se destacar de acordo com os estudos: o estado geral de saúde ruim, emagrecimento, síndrome do pânico, problemas estomacais, dores de cabeça, sobrepeso, alergias, ansiedade, problemas para dormir, estresse, insônia, falta de apetite, indigestão, tristeza, infelicidade e, nos casos mais graves, a morte $(24,25,28,29,32)$. Além disso, elas lidam com sentimento de vergonha e humilhação. A violência doméstica pode levar à limitação 
de mobilidade em pessoas idosas, isso está intimamente relacionado com a qualidade de vida do indivíduo, quanto menor a mobilidade, pior a qualidade de vida (34).

A dinâmica desse ambiente de violência é caracterizada pela coabitação da mesma residência pela vítima e pelo agressor $(15,18,21,24)$, os quais têm uma relação de dependência mútua, seja física ou financeiramente (28). É comum um cenário de desestruturação familiar, pobreza e uso abusivo de álcool e/ou drogas $(15,16,29,35,36)$.

Uma estratégia utilizada pelos agressores para evitar que ocorram denúncias é o isolamento social da idosa. A vítima é impedida indiretamente de pedir ajuda aos parentes e conhecidos, o agressor acaba por isolá-la. Isso impossibilita que a pessoa idosa acesse os serviços de segurança pública especializados. Dessa forma, a falta de outros vínculos prejudica a denúncia $(26,29)$.

Segundo o trabalho realizado por Lopes et al. (31), 4\% das pessoas idosas que sofreram agressões em Caruaru/PE não resistiram e foram a óbito. Em adição a isto, Santana et al. (26) apresenta em sua pesquisa que $41 \%$ das pessoas idosas que denunciaram a violência em Aracaju/SE, já haviam passado pela mesma situação anteriormente. A correlação desses dados mostra que não denunciar as violências sofridas, pode trazer mais sofrimento às pessoas idosas.

Entretanto, a família é uma prioridade para as idosas, por isso que muitas vezes relevam ou escondem as agressões sofridas para preservar sua família (4). Dentre as estratégias usadas para enfrentar a violência estão: evitar o confronto com o agressor, procurar apoio em outros membros da família e na própria comunidade. Mas, segundo estudos, as idosas desconhecem os equipamentos de apoio da rede de atenção $(21,25,37)$. Isso acaba impossibilitando uma análise real da prevalência da violência contra pessoas idosas (25).

Apesar de não denunciar, a pessoa idosa expressa sentimentos como: temor da retaliação ou represália e de levar a culpa por gerar um conflito, a vergonha da situação e o medo de ser colocada em uma instituição de longa permanência (21).

A aposentadoria ou mesmo a renda proveniente do benefício assistencial da pessoa idosa acabam compondo o orçamento familiar, ou seja, o próprio agressor, muitas vezes depende da renda da pessoa idosa, levando a uma possibilidade de violência financeira $(15,16,26,30,35)$. Dessa forma, a idosa tem a função de provedora fundamental na estrutura dessa família. A falta de paciência dos familiares, o interesse de cuidar da pessoa idosa apenas pelo dinheiro que esta possui e a dificuldade da sociedade em geral, de valorizar e se colocar no lugar dessas pessoas foram fatores relevantes relacionados com a violência contra elas $(17,26,30)$.

As principais dificuldades para a ação dos mecanismos sociais de proteção à pessoa idosa são: vítimas não relatam a violência, pouca participação da comunidade, recurso financeiro insuficiente, pouca articulação intersetorial, desconhecimento dos recursos disponibilizados e ausência de política específica $(30,36)$.

Acrescido disso, em Viçosa/MG, um trabalho feito por Pereira e Loreto (37), dos 306 casos de violência doméstica, 17 eram contra mulheres idosas. Apesar das vítimas afirmarem terem conhecimento sobre a Lei Maria da Penha e o Estatuto do Idoso, não sabiam que ao fazer uma denúncia de violência estariam acionando essas duas ferramentas. Os dados da pesquisa confirmam também que, na maioria dos casos, as mulheres tendem a não dar prosseguimento com os processos contra a violência e acabam desistindo.

Segundo Lopes et al. (31), os investimentos em políticas públicas que garantam qualidade a essa faixa etária ainda são incipientes. Uma das estratégias, segundo Paiva e Tavares (22), para diminuir a violência contra a pessoa idosa ou para melhorar a notificação dos casos, é a mudança na formação do profissional de saúde, com novas 
diretrizes curriculares associadas às políticas públicas de saúde e a inclusão da temática violência.

Dessa forma, focando em atenção primária e na estratégia saúde da família, os profissionais saberiam como atuar nessas situações e construiriam ações de prevenção e proteção às pessoas idosas $(19,22,38)$. A visita domiciliar pelos profissionais de saúde é fundamental para conhecer o contexto familiar e assim intervir se necessário na dinâmica do ambiente. Além de realizar um acompanhamento contínuo $(19,22,39)$.

Quanto as limitações do estudo, vale ressaltar: literatura escassa sobre o tema, algumas regiões do Brasil não se encontravam representadas nos estudos selecionados e nem todos os artigos utilizados dialogavam com a experiência pessoal das pessoas idosas. Entretanto, os resultados apresentados são de extrema relevância para a investigação dos casos suspeitos de violência, para a melhor atuação dos mecanismos sociais de proteção às pessoas idosas e para a resolução dos casos, uma vez que, pode-se evitar as sequelas: físicas, psicológicas e sociais que são geradas para as idosas brasileiras.

\section{Considerações finais}

Apesar da grande diversidade cultural no território brasileiro, os trabalhos analisados trouxeram padrões quanto ao: perfil da vítima e do agressor, aos tipos mais frequentes de violência sofridas pelas idosas e as sequelas deixadas, ao local de ocorrência e os motivos para as idosas não fazerem as denúncias.

Pode-se concluir que a violência contra a mulher idosa se encontra pautada em aspectos patriarcais e machistas que acompanham a sociedade. Além disso, foi comprovado a necessidade da criação de políticas públicas que as protejam, uma vez que essas mulheres estão em dois grupos de vulnerabilidade social: mulher e idoso, e que os profissionais da saúde estejam capacitados para identificar cenários suspeitos.

\section{Referências}

1. Moreira V, Boris GDJB, Venâncio N. O estigma da violência sofrida por mulheres na relação com seus parceiros íntimos. Psicol. Soc. 2011; 23(2): 398-406.

2. da Cunha BM. Violência contra a mulher, direito e patriarcado: perspectivas de combate à violência de gênero. Anais XVI Jornada de Iniciação Científica de Direito da UFPR. 2014; 1(5): 149-170.

3. Brasil. Lei $\mathrm{n}^{\circ}$. 11.340 de 7 de agosto de 2006. Lei Maria da Penha. Coúbe a violência doméstica e familiar contra a mulher. Presidência da República, 2006.

4. Martins MB. Violência silenciada: violência física e psicológica contra idosos no contexto familiar [Dissertação]. Manaus: Universidade Federal do Amazonas, Mestrado em Educação; 2012.

5. Santigo RA, Coelho MTAD. A violência contra a mulher: antecedentes históricos. Rev. Seminário Estudantil de Produção Acadêmica. 2007; 11(1): 1-19.

6. Lopes EDS, Ferreira AG, Pires CG, Moraes MCS, D`Elboux MJ. Maus-tratos a idosos no Brasil: uma revisão integrativa. Rev. Bras. Geriatr. Gerontol. 2018; 21(5): 652-662.

7. Perissé C, Marli M. Caminhos para uma melhor idade. Retratos a revista do IBGE. 2019; 16:20-25.

8. Brasil. Lei federal $n^{\circ} 10.741$ de 01 de outubro de 2003. Dispõe sobre o Estatuto do Idoso. Brasília, DF: Secretaria Especial dos Direitos Humanos, 2004.

9. Araneda GN. Violência contra pessoas idosas: uma realidade oculta. Caderno de violência contra a pessoa idosa - Secretária Municipal da Saúde São Paulo. Violência doméstica contra a pessoa idosa: orientações gerais. Coordenação de Desenvolvimento de Programas e Políticas de Saúde - CODEPPS. 2007; 21-22.

10. Brasil. Secretaria de Direitos Humanos da Presidência da República. Manual de enfrentamento à violência contra a pessoa idosa: é possível prevenir, é necessário superar. Brasília, 2013.

11. Minayo MCS. Violência contra idosos: o avesso do respeito à experiência e à sabedoria. Brasília (DF): Secretaria Especial dos Direitos Humanos. 2 edição, 2005.

12. Ministério da Mulher, da família e dos direitos humanos [base de dados online]. Balanço Anual do Disque Direitos Humanos em 2018. 2019. Acesso em 10 de julho de 2020. 
13. De Castro AP. Ecos da violência: significados e repercussões em idosos [Tese]. Rio de Janeiro: Escola Nacional de Saúde Pública Sergio Arouca, Doutorado em Saúde Pública; 2013

14. Taveira LM, de Oliveira MLC. Perfil da violência cometida contra a pessoa idosa registrada no disque direitos humanos no período de 2011- 2015 no Brasil. Geriatr. Gerontol. Aging. 2020; 14(2): 120-127.

15. Faustino AM, Moura LBA, Gandolfi L. Perfil sociodemográfico y situaciones de violencia contra ancianos: estudio descriptivo. Online Braz J Nurs. 2014; 13(4): 529-536.

16. Florêncio MVL. Rastreamento de violência contra pessoas idosas cadastradas pela estratégia de saúde da família em João Pessoa-PB [Tese]. Porto Alegre: Pontifícia Universidade Católica do Rio Grande do Sul, Doutorado em Gerontologia Biomédica; 2014.

17. Irigaray TQ, Esteves CS, Pacheco JTB, Grassi-Oliveira R, Argimon IIL. Maus-tratos contra idosos em Porto Alegre, Rio Grande do Sul: um estudo documental. Estud. psicol. (Campinas). 2016; 33(3): 543-551.

18. De Almeida CO. "Em que espelho ficou perdida a minha face?" Um estudo sobre velhice e violência doméstica em Fortaleza. Fortaleza: Universidade Federal do Ceará, 2013. Dissertação de mestrado em Sociologia.

19. Rodrigues IS. Violência contra a pessoa idosa: realidades e desafios [Dissertação]. Teresina: Universidade Federal do Piauí, Mestrado em Enfermagem; 2015

20. Mallet SM. Denúncias e ações de enfrentamento à violência intrafamiliar: Conselho Municipal do Idoso de Belo Horizonte 2011-2013 [Dissertação]. Belo Horizonte: Universidade Federal de Minas Gerais, Mestrado em Promoção da Saúde e Prevenção da Violência; 2015.

21. Laroque MF. Análise da violência contra idosos no município de Pelotas - RS no ano de 2012 [Dissertação]. Pelotas: Universidade Católica de Pelotas, Mestrado em Política Social; 2014.

22. De Paiva MM, Tavares DMS. Physical and psychological violence against the elderly: prevalence and associated factors. Rev. Bras. Enferm. 2015; 68(6):1035-41.

23. Matos NM, Albernaz EO, Sousa BB, Braz MC, Vale MS, Pinheiro HA. Profile of aggressors of older adults receiving care at a geriatrics and gerontology reference center in the Distrito Federal (Federal District), Brazil. Rev. bras. geriatr. Gerontol 2019; 22(5): e190095.

24. Bolsoni CC, Coelho EBS, Giehl MWC, d'Orsi E. Prevalence of violence against the elderly and associated factors - a population based study in Florianópolis, Santa Catarina. Rev. bras. geriatr. gerontol 2016; 19(4):671-682.

25. Machado DR, Kimura M, Duarte YAO, Lebrão ML. Violência contra idosos e qualidade de vida relacionada à saúde: estudo populacional no município de São Paulo, Brasil. Ciênc. saúde coletiva 2018; 25(3): 1119-1128.

26. De Santana RG, Oliveira LES, Cruz MHS, Silva NL, Rabelo SF, Santos VN. Mapeando expressões de violência de gênero praticadas contra idosos/as em Aracaju. Anais do $16^{\circ}$ Congresso Brasileiro de Assistentes Sociais, Brasília, DF. 2019; 16(1): 1-12.

27. Guimarães APS, Górios C, Rodrigues CL, Armond JE. Notification of intrafamily violence against elderly women in the city of São Paulo. Rev. bras. geriatr. gerontol. 2018; 21(1):91-97.

28. Damaceno DG, Alarcon MFS, Sponchiado VBY, Marin MJS. Mulheres idosas vítimas de violência: estudo de casos múltiplos. Investigação Qualitativa em Saúde. 2018; 2: 779-788.

29. Damasceno CKCS, de Sousa CMM, Moura MEB. Violência contra pessoas idosas registrada em delegacia especializada de segurança e proteção ao idoso. Rev enferm UFPE on line. 2016; 10(3): 949-57.

30. Lourenço LM, De Paula GV. Crença de gestores de Saúde em relação à violência doméstica. Gerais, Rev. Interinst. Psicol. 2020; 13(1):1-18.

31. Lopes LGF, Leal MCC, de Souza EF, da Silva SZR, Guimarães NNA, da Silva LSR. Violência contra a pessoa idosa. Rev enferm UFPE on line. 2018; 12(9):2257-68.

32. Souto RQ, Merighi MAB, Guruge S, de Jesus MCP. Older Brazilian women's experience of psychological domestic violence: a social phenomenological study. Int J Equity Health. 2015; 14:44.

33. De Rezende MM. Violência contra o idoso no estado de Minas Gerais: análise das notificações em 2009 e 2012 [Dissertação]. Uberaba: Universidade Federal do Triângulo Mineiro, Mestrado em Atenção à Saúde; 2013

34. Guedes DT. Prevalência, fatores associados e efeitos da violência doméstica na mobilidade em idosos: evidências do estudo imias (international mobility in aging study) sob a perspectiva epidemiológica do curso da vida [Tese]. Natal: Universidade Federal do Rio Grande do Norte, Doutorado em Ciências da Saúde, Centro de Ciências da Saúde; 2015

35. Bohm V. Violência contra pessoas idosas: narrativas de agressores [Tese]. Porto Alegre: Universidade Federal do Rio Grande do Sul, Doutorado em Educação; 2016.

36. Silveira L. Gênero, velhice e geração: a violência familiar contra a mulher idosa em Vitória (ES), 20102012 [Dissertação]. Vitória: Universidade Federal do Espírito Santo, Mestrado em História; 2015 
37. Pereira RCBR, de Loreto MDS. A Violência Doméstica Contra a Mulher Idosa: A busca pelos Aparatos Sociais de Proteção. In: Anais VII Congresso Internacional do Envelhecimento Humano. Campina Grande, PB; 2019.

38. Barros APM. Percepções de idosos e profissionais do serviço de convivência em sobral sobre violência institucional nos serviços de saúde [Dissertação]. Sobral: Universidade Federal do Ceará; Mestrado em Saúde da Família; 2016

39. Raposo MAM. Violência contra a pessoa idosa: o olhar dos profissionais de saúde de um hospital universitário [Dissertação]. Vitória: Universidade Federal do Espírito Santo, Mestrado em Enfermagem; 2013. 